\title{
ETHOLOgICAL STUdies USING TWINS: DOING WHat COMES NATURALLY
}

\author{
Nancy L. Segal \\ Department of Psychology, California State University, Fullerton, CA, USA \\ nsegal@fullerton.edu
}

\begin{abstract}
Combining ethological methods with twin and adoption designs enables the testing of novel hypotheses regarding human behavior. Specifically, genetic influences on behaviors expressed in naturalistic and semi-naturalistic social settings can be observed, affording insights and ideas that might otherwise be missed. This article briefly reviews the logic of twin and adoption research methods, then illustrates their application in a series of ethologically-based studies concerning cooperation and competition, social relatedness and tacit coordination (decisionmaking). Future studies that would potentially benefit from this approach are suggested.
\end{abstract}

Keywords: identical twins, fraternal twins, cooperation, social closeness, decision-making.

\section{INTRODUCTION}

Everyone enjoys watching people with a glass of wine in hand, crafting stories about who they are and how they got that way. Human ethological analysis is really scientific people watching--what people do when they are free to act naturally is fascinating to witness, and ethological researchers are well-positioned to capture these behaviors and to consider their theoretical significance and implications.

Bringing genetically and environmentally informative kinships to ethological analyses adds a novel dimension to the findings, namely opportunities to consider the effects of 
shared genes and/or shared environments on behavioral processes and outcomes. Some of these kinships include identical twins, fraternal twins and virtual twins, as explained below. Another interesting pair is composed of individuals who look a lot alike physically, but who are genetically unrelated. Such pairs have not yet been used in ethological studies, but suggestions as to how they might be included are presented.

\section{TWIN AND ADOPTION DESIGNS: A PRIMER}

Identical twins result when a single fertilized egg divides between the first and fourteenth day after conception (Segal, 2000). Most relevant texts report that identical twins share $100 \%$ of their genes; however, mutations and/or structural variations in DNA can make identical twins not quite genetic duplicates. Epigenetic events (processes associated with gene expression) may also cause identical twins to differ in selected physical or behavioral characteristics. Lastly, differences in intrauterine conditions and/or life time experiences may also explain the less than perfect similarity between identical twins. Regardless, identical twins are very strongly matched in appearance and behavior (Segal, 2017). A more appropriate scientific label for identical twins is monozygotic (MZ), indicating that they formed from a single zygote, without implying that they are strictly identical.

Fraternal twins result when a woman releases two eggs at the same time, both of which are fertilized by separate sperm (Segal, 2000). These twins, which may be samesex or opposite-sex, share $50 \%$ of their genes, on average, by descent, just like ordinary full siblings. Fraternal twins vary on a spectrum of genetic relatedness-it has, for example, been estimated that fraternal twins share between $42 \%$ and $58 \%$ of their genes (Martin, 2016). It is also possible for fraternal twins to have different fathers in the event that their mother had sexual relations with different males close in time, an event called superfecundation. Such twins would share $25 \%$ of their genes, on average, just like halfsiblings. The frequency with which such twinning occurs is unknown, because some cases of superfecundation may go undetected. It is important to identify such twins in research because their presence might affect the results to some extent, especially when sample sizes are modest (Segal, 2017). The appropriate scientific label for fraternal twins is dizygotic (DZ), indicating that they formed from two different zygotes. The terms MZ and $\mathrm{DZ}$ will be used throughout the remainder of this article to maintain the accurate biological distinction between the two types of twins.

Virtual twins (VTs) are same-age unrelated individuals raised together from very early infancy. These pairs, which generally include two adoptees or one adoptee and one biological child, replicate twinship, but without the genetic link. The members of these pairs are closely matched with respect to time of entry into their family as well as their residential histories, so they surpass ordinary adopted brothers and sisters in twin-sibling comparisons (Segal, McGuire \& Hoven Stohs, 2012).

A critical first step in twin research is the accurate classification of the different pairs as MZ or DZ (Segal, 2017). This can be accomplished by comparing the twins' similarity across approximately fifteen DNA markers. Exact matches indicate $\mathrm{MZ}$ twins, while mismatches indicate DZ twins; it would be very rare for DZ twins to match across all fifteen of these markers. In the event that DNA analysis cannot be performed then a 
standard physical resemblance questionnaire that shows high agreement with DNA test results can be substituted (Nichols \& Bilbro, 1966). It is not appropriate to diagnose twin type from assessments of twins' physical resemblance alone because some $\mathrm{MZ}$ twins do not look identical due to birth trauma or other events affecting only one twin or affecting both twins differently, and some DZ twins look very similar.

\section{TWIN AND ADOPTION RESEARCH DESIGNS}

Sir Frances Galton introduced a twin-based approach to studying human behavioral and physical characteristics in the late 1800s (Galton, 1875). At that time, the biological bases of twinning were unknown, but Galton reasoned that twins who look alike share all of their heredity, while twins who do not look alike share less. The classic twin design is elegant, but also simple, in that it compares the resemblance between MZ twins and DZ twins with reference to traits of interest. Genetic influence is indicated by greater MZ than $\mathrm{DZ}$ twin resemblance.

There are a number of interesting and informative variations on the classic twin design (see Segal, 1990; 2000), but the two that are most relevant to ethological analysis are the "twins as couples" design and twins reared apart from birth. The "twins as couples" design does not compare the similarity of twin A and twin B; instead, this design compares social-interactional outcomes and processes expressed by $\mathrm{MZ}$ and $\mathrm{DZ}$ twin pairs as they interact with one another. Such studies may include having twins engage in joint games, complete shared tasks or solve common problems, with an emphasis on observing their cooperative and competitive tendencies in natural and semi-naturalistic settings. Most importantly, these studies offer a look at how relative genetic relatedness affects human social relations. The rare pairs of MZ twins reared apart (MZA) are valuable because they yield pure estimates of genetic influence on behavior, while DZ twins reared apart (DZA) provide an important comparison group. Virtual twins, the counterparts to MZA twins, give scientists a pure estimate of environmental influence. This information is summarized in Table 1.

Table 1: Genetically and Environmentally Informative Kinships.

\begin{tabular}{lll}
\hline Pair & Label & Relatedness \\
\hline Monozygotic (Identical) Twins & MZ & $100 \%$ shared genes; shared environment \\
Dizygotic (Fraternal) Twins & DZ & $50 \%$ shared genes (average); shared environment \\
Monozygotic Twins Reared Apart & MZA & $100 \%$ shared genes; different environment \\
Dizygotic Twins Reared Apart & DZA & $50 \%$ shared genes (average); different environment \\
Virtual Twins & VT & $0 \%$ shared genes; shared environment \\
\hline
\end{tabular}


Some of the studies reviewed below have adapted methods used in non-human ethological work for human ethological research. Reviews of other naturalistic studies involving twins are available in Segal $(2011,2017)$.

\section{“Twins-as-Couples:” Puzzle Completion}

Developmental social genetics focuses on how the genotypes of two or more individuals affect social-interactional processes and outcomes. Some of the most revealing studies to emerge from this approach concerned different breeds of dogs placed in various seminaturalistic experimental settings (Scott, 1977). Some of the methods in those studies have been adapted for studies of social behavior using $\mathrm{MZ}$ and $\mathrm{DZ}$ twin pairs.

The first twin study I conducted compared expressions of cooperation, competition and altruism within MZ and DZ twin pairs whose mean age was 7.94 years (S.D. = 1.37) as they engaged in joint puzzle completion (Segal, 1984). This was a semi-naturalistic task-naturalistic because completing a puzzle is an activity that twins and siblings often do together, but it is not fully naturalistic because the same puzzle (picture of a puppy) was presented to all pairs with the pieces uniformly arranged and with the instructions to "solve the puzzle together." These sequences were recorded using Super $8 \mathrm{~mm}$ film and submitted to separate sets of judges for two types of analysis.

In the first analysis both twins' faces were concealed, except where indicated, so that knowledge of twin type would not bias the scoring; this was done by placing an opaque card over the lens. The MZ and DZ twins were then compared with reference to a number of variables, including:

- Time working until successful completion $(\mathrm{MZ}<\mathrm{DZ})$

- Puzzle equidistant between the twins (MZ $>\mathrm{DZ})$

- Positive gestures (one face hidden at a time) $(\mathrm{MZ}>\mathrm{DZ})$

- Positive facial expressions (one face hidden at a time) $(\mathrm{MZ}>\mathrm{DZ})$

- Mutuality in facial expressions (both faces visible) $(\mathrm{MZ}>\mathrm{DZ})$

The main findings supported greater cooperation within MZ than DZ twin pairs. [More MZ twins than DZ twins completed the puzzle successfully; however, the DZ twins who completed the puzzle within the time limits worked significantly faster than the MZ twins. Perhaps these DZ twins worked mostly at an individual level.] The findings were unrelated to parents' beliefs about twin type, the twins' perceived degree of physical similarity and twin club membership.

The second analysis, in which the twins' features were visible, obtained global impressions of the twins' behaviors from three clinical psychologists with respect to:

$$
\begin{array}{lll}
\text { Mutuality in Goal }(\mathrm{MZ}>\mathrm{DZ}) & 0=\text { Individual effort } & 10=\text { joint effort } \\
\text { Cooperation }(\mathrm{MZ}>\mathrm{DZ}) & 0=\text { competitive } & 10=\text { cooperative } \\
\text { Accommodation }(\mathrm{MZ}>\mathrm{DZ}) & 0=\text { very little } & 10=\text { very much } \\
\text { Role division }(\mathrm{MZ}<\mathrm{DZ}) & 0=\text { not evident } & 10=\text { very evident }
\end{array}
$$




$$
\begin{array}{lll}
\text { Involvement }(\mathrm{MZ}>\mathrm{DZ}) & 0=\text { unequal } & 10=\text { equal } \text { or balanced } \\
\text { Contribution }(\mathrm{MZ}>\mathrm{DZ}) & 0=\text { unequal } & 10=\text { equal } \text { or balanced }
\end{array}
$$

Again, this analysis supported greater cooperation within MZ than DZ twin sets. Not surprisingly, the only measure in which $\mathrm{DZ}$ twins exceeded the $\mathrm{MZ}$ twins was role division (Segal, 2002).

\section{“Twins-as-Couples:” Tacit Coordination (Decision-Making)}

Tacit coordination refers to circumstances in which "two parties have identical interests and face the problem not of reconciling interests but only of coordinating their actions for their mutual benefit when communication is impossible" (Schelling, 1960, p. 54). It was expected that $\mathrm{MZ}$ twins would show greater coordination, or matching, on a decision-making task than DZ twins who would, in turn, show greater coordination than VTs.

Participants in this study were 7-13-year-old MZ twin pairs $(\mathrm{n}=53), \mathrm{DZ}$ twin pairs $(\mathrm{n}=85)$ and virtual twin $(\mathrm{VT})$ pairs $(\mathrm{n}=42)$ (Segal, McGuire, Miller, \& Havlena, 2008). The first task (individual) was to independently answer 20 questions, such as name a movie, name an ice cream flavor and name a book. The second task (coordination) was to independently answer the same questions, but in a way that the twins would come up with the same answers, what can be considered to be nonnegotiated consensus. As expected, the $\mathrm{MZ}$ twins outscored the $\mathrm{DZ}$ twins, and the $\mathrm{DZ}$ twins outscored the VTs in both conditions, although the twin type $\mathrm{x}$ condition interaction was not statistically significant. It was suggested that clear indicators of similarity, such as those associated with tacit coordination, may solidify social bonds, leading to mutually desired goals. This study was repeated several years later using 43 MZ twin pairs and $34 \mathrm{DZ}$ twin pairs between the ages of 12 and 59 years of age (Segal, Munson, Marelich, Goetz, \& McGuire, 2013). Again, the MZ twins outperformed the $\mathrm{DZ}$ twins in the number of matches, especially in the coordination condition, although the twin type $\mathrm{x}$ condition interaction was not statistically significant. New data continue to be gathered from older $\mathrm{MZ}$ and $\mathrm{DZ}$ twin pairs in this ongoing study.

\section{"Twins-as-Couples:" Nearest Neighbor or "Twins in the Wild"}

The Nearest Neighbor (NN) Technique was applied by Kummer (1968) for the study of social and spatial affinities of hamadryas baboons, as a function of age and sex. In brief, this method involved recording the nearest neighbor of a designated target subject. Kummer's approach was successfully adapted for analyzing the play preferences of young children (see Freedman, 1979), and seemed very well suited for doing the same with MZ and DZ twins (Segal, 1997). It was expected that MZ co-twins (pair members) would be found more closely situated during free play than DZ twins and that there would be more frequent occurrences of meaningful social interaction (either verbal or non-Verbal) between them. Twelve pairs of twins, $4 \mathrm{MZ}$ hand-concordant pairs (HC; same hand preference), $4 \mathrm{MZ}$ hand-discordant pairs (HD; different hand preference) and $4 \mathrm{DZ}$ pairs, with a mean age of 8.26 years (S.D. $=1.34)$ and evenly divided by sex, participated in this pilot study. It was of interest to see if $\mathrm{HD}$ pairs might differ from $\mathrm{HC}$ pairs due to possible differences in brain organization. Two observers situated themselves on the 
periphery of the twins' play area at their school and recorded the various interactional events at 10-second intervals indicated by beeps; beeps were emitted by a common device attached to ear pieces that were worn by each observer. The following scoring system was applied:

1: $1^{\text {st }} \mathrm{NN}+$ interaction (target twin is spatially closest to the co-twin, and there is evidence of interaction, e.g., talking, touching).

2: $2^{\text {nd }} \mathrm{NN}+$ interaction (target twin is spatially second closest to the co-twin, and there is evidence of interaction)

3: $3^{\text {rd }} \mathrm{NN}+$ interaction (target twin is spatially third closest to the co-twin, and there is evidence of interaction)

4: $1^{\text {st }} \mathrm{NN}$ (target twin is spatially closest to the co-twin, but without evidence of interaction)

5: $2^{\text {nd }} \mathrm{NN}$ (target twin is spatially second closest to the co-twin, but without evidence of interaction)

6: $3^{\text {rd }} \mathrm{NN}$ (target twin is spatially third closest to the co-twin, but without evidence of interaction)

7: Verbal interaction (twins communicate verbally but are not spatially close to one another; e.g., shouting across the play area)

8: Non-verbal interaction (twins communicate by gesture, but are not spatially close to one another, e.g., waving)

9: Uncertain (unclear observation)

10: No interaction (twins are neither spatially close, nor interacting in any way.)

The data were tabulated in two ways. The first was the number of events that were observed for each individual twin. The second was the number of matched events that were recorded for each twin. For example, both co-twins might receive simultaneous scores of "1" or "2," constituting a match. However, it was possible for one twin to be scored as " 2 " at the same time that his or her co-twin was scored as " 3 ," a combination that would not be considered a match.

At the highest levels of closeness, MZ-HD twins were found together most often, followed by MZ-HC pairs and lastly the DZ pairs. The MZ pairs exceeded the DZ pairs on all measures except for the frequency of 0 s and 4-4 matches. The sample sizes were small, but the results were encouraging so that larger studies of both twins and virtual twins would be of interest. Unfortunately, the time-consuming aspect of ethological studies can pose considerable challenge to obtaining the large sample sizes that are possible with pencil and paper and questionnaires. However, written surveys cannot capture the richness and depth of naturally expressed behaviors.

\section{Twins Reared Apart}

In 2006, I launched a prospective developmental study of young Chinese twins raised apart from birth (Segal, Stohs, \& Evans, 2011; Segal, Tan, \& Graham, 2015). Their separation resulted indirectly from China's 1979 One-Child Policy that limited urban families to one child and rural families to two. This policy, coupled with that culture's 
preference for sons, led to the abandonment of tens of thousands of infant daughters, among them twins, who were adopted by different families around the world. I have identified a number of these pairs and have studied their mental and social development from an early age.

Of special interest is the nature of the young twins' behaviors when they meet for the first time--self-report studies using adult twins have indicated greater social closeness and familiarity among MZA than DZA twins, over and beyond their feelings toward the adoptive siblings with whom they were raised (Segal, Hershberger, \& Arad, 2003). A plausible interpretation of these findings is that MZ twins' greater perceptions of behavioral similarities trigger feelings of affiliation that work to sustain that relationship. Thus, it was important to know if these tendencies would also characterize much younger reared-apart twins.

Parents were present for the twins' first reunions, as well as their first departures, and were asked to provide their direct observations (Segal, et al., 2011). Data have now been analyzed for the first ten pairs, organized according to age at first meeting (younger than 18 months and older than 18 months). This division was suggested, based on the increased social complexity of children's behavior during the second year of life (Rubin, Bukowski, \& Parker 2006). Parental descriptions of children's behaviors were classified as high (intense interest and interaction); moderate (interested, but not immediately drawn to or focused on one another); or low (little attraction or interest). Departures were categorized as high (grief); moderate (sad, but accepting); or low (no reaction).

The majority of older pairs displayed high levels of attraction upon first meeting, and showed intense grief at the time of departure, whereas younger pairs were less consistent. The older MZA and DZA twins showed strong attraction for one another at their first meeting, but no clear twin group trend was observed. DZA twin departures were somewhat more variable than the MZA twin departures. These data, while suggestive and generally consistent with the literature on twin relationships, are based on small sample sizes so need to be viewed cautiously.

\section{SUMMARY}

Joining genetically informative kinships, such as $\mathrm{MZ}$ twins, DZ twins and virtual twins with ethological analysis allows assessments of genetic and environmental influences on social interaction. The same kinds of naturalistic and semi-naturalistic methods used with non-twins can easily be accommodated for research using twins and other pairs. No one has yet considered ethological analyses of genetically unrelated individuals who resemble one another physically, although studies have shown that the individuals lack personality similarity and generally indicate little social attraction to one another (Segal, 2013, Segal, Graham, \& Ettinger, 2013). However, observing the behaviors of these pairs during the completion of joint activities would offer another approach to the class of questions considered here, namely the effects of genetic commonality on social interaction.

Ethological research is both informative and fun as I indicated in the opening sections of this paper. It allows for considerable creativity in the recording and interpretation of 
behavior, adding to what we know and can know about all aspects of human functioning and development.

\section{REFERENCES}

Freedman, D.G. (1979). Human sociobiology: A holistic approach. New York, NY: Free Press.

Kummer, H. (1968). Social organization of hamdryas baboons: A field study. Chicago: University of Chicago Press.

Dr. N. Martin, personal communication, July 19, 2016. Also see Visscher, Medland, Ferreira, Morley, Zhu, Cornes et al. (2006). Assumption-free estimation of heritability from genome-wide identity-by-descent sharing between full siblings, PLoS Genetics, 2(3), e41. DOI

Nichols, R. C., \& Bilbro, W.C. (1966). The diagnosis of twin zygosity. Human Heredity, 16(3), 265-275.

Rubin, K.H., Bukowski, W.M., \& Parker, J.G. (2006). Peer interactions, relationships, and groups. In N. Eisenberg (Ed.), Handbook of child psychology, 3 (6th ed.) (pp. 571-645). New York: John Wiley \& Sons. DOI

Segal, N.L. (1984). Cooperation, competition and altruism within twin sets: A reappraisal. Ethology \& Sociobiology, 5(3), 163-177. DOI

Segal, N.L. (1997). Twin research perspective on human development. In N.L. Segal, G.E. Weisfeld, \& C.C. Weisfeld (Eds.), Uniting psychology and biology: Integrative perspectives on human development (pp. 145-173). Washington, D.C.: APA Press. DOI

Segal, N.L. (2000). Entwined Lives: Twins and what they tell us about human behavior. N.Y.: Plume.

Segal, N.L. (2002). Co-conspirators and double-dealers: A twin film analysis. Personality and Individual Differences, 33(4), 621-631. DOI

Segal, N.L. (2013). Personality similarity in unrelated look-alike pairs: Addressing a twin study challenge. Personality and Individual Differences, 54(1), 23-28. DOI

Segal, N.L. (2017). Twin mythconceptions: False beliefs, fables, and facts about twins. San Diego, CA: Elsevier. DOI

Segal, N.L., Graham, J.L., \& Ettinger, U. (2013). Unrelated look-alikes: A replicated study of personality similarity and new qualitative findings on social relatedness. Personality and Individual Differences, 55,(2) 169-176. DOI

Segal, N.L., Hershberger, N.L., \& Arad, S. (2003). Meeting one's twin: Perceived social closeness and familiarity. Evolutionary Psychology, 1, 70-95. DOI 
Segal, N.L., McGuire, S.A., \& Hoven Stohs, J. (2012). What virtual twins reveal about general intelligence and other behaviors. Personality and Individual Differences, 53(4), 405-410. DOI

Segal, N.L., McGuire, S.A., Miller, S., \& Havlena, J. (2008). Tacit coordination in monozygotic twins, dizygotic twins and virtual twins: Effects and implications of genetic relatedness. Personality and Individual Differences, 45(7), 607-612. DOI

Segal, N.L., Munson, J.E., Marelich, W.D., Goetz, A.T., \& McGuire, S.A. (2013). Meeting of minds: Tacit coordination in monozygotic and dizygotic adolescent and adult twins. Personality and Individual Differences, 58, 31-36. DOI

Segal, N.L., Tan, T.X., \& Graham, J.L. (2015). Twins and virtual twins: Do genetic (as well as experiential) factors affect developmental risks? Journal of Experimental Child Psychology, 136, 55-69. DOI 